\title{
Teaching Reform Exploration of Principle and Application of DSP
}

\author{
Shuang Zhang ${ }^{1,2}$, Yuping Qin ${ }^{1}$ and Yihe $\mathrm{Liu}^{2 *}$ \\ ${ }^{1}$ The Engineering \& Technical College of Chengdu University of Technology, Leshan, 614000, P.R. \\ China \\ ${ }^{2}$ College of computer science, Neijiang Normal University, Neijiang, 641000, P.R. China \\ zhangshuanghua1@126.com, qingyuping520025@126.com, liu_yihe@163.com \\ *The corresponding author
}

Keywords: Teaching Reform; DSP; Principle and application; Teaching methods

\begin{abstract}
Principle and application of DSP is an important basic professional course of the communication engineering major, the automation major, the measurement $\&$ control technology and instrumentation major, the electrical engineering major in institutions of higher education. This course is characterized by rich content, abstract concepts, complex principles and strong practicality. Learning this course is slightly difficult for students, but this course is critical for their development. In our college, it is the main objective to cultivate applied talents. In order to realize the personnel training objective under the new education pattern, it is necessary to reform the original teaching contents, teaching methods, teaching means, practical teaching and course assessment.
\end{abstract}

\section{Introduction}

Principle and application of DSP is an important basic professional course of the communication engineering major, the automation major, the measurement $\&$ control technology and instrumentation major, the electrical engineering major in institutions of higher education. This course is characterized by rich content, abstract concepts, complex principles and strong practicality. Learning this course is slightly difficult for students, but this course is critical for their development.

What should be taught to students in this course? How to teach? How to assess? I have been thinking for a long time. In our college, it is the main objective to cultivate applied talents. In order to realize the personnel training objective under the new education pattern, it is necessary to reform the original teaching contents, teaching methods, teaching means, practical teaching and course assessment.

\section{Reform of Teaching Contents}

Since DSP emerged in 1980s, it has developed rapidly in the past several decades. With the arrival of the new global technical revolution, DSP's content has developed to a new level, so the teaching content should timely reflect era characteristics and the direction of scientific and technological development, so as to meet the needs of the objective situation for talent cultivation. However, the teaching hours is limited, totaling 34 hours; therefore, when selecting teaching contents, it is necessary to seriously select teaching textbooks and teaching contents, and refine lecture topics.

Selection of Teaching Textbooks. The teaching textbook is the basis of a course. We refer to a number of overseas and domestic textbooks according to teaching needs, and select the teaching textbook and auxiliary teaching materials suitable for current students in combination with the latest development of digital signal processing theory and technology.

Selection of Teaching Content. In the case of limited teaching hours, in the teaching process, we pay special attention to selection and partitioning of teaching contents. The key to elaborately refine lecture topics is how to realize "fewer but better" teaching content, so as to improve the classroom 
efficiency. Its premise is to organize lecture topics and refine the essence based on the selection of teaching contents.

After several years of teaching practice, we think that teaching of the course should abide by the principle of "Teaching the basic concepts and mastering the basic skills dominate and consideration is also given to comprehensiveness and systematicness of contents". The course content is reduced to the following knowledge points based on several DSP textbooks:

(1) Hardware: CPU, bus structure, storage, and so on;

(2) Software: use of the integrated development environment, DSP instruction system, program structure, $\mathrm{C}$ language programming of DSP;

(3) Development and application of digital signal processors.

\section{Reform of Teaching Methods and Means}

Principle and application of DSP is offered after students have learned Principle and Application of Single Chip Computer. The following reform and attempt are carried out in teaching means and methods.

Teaching Hours. Total class hours of Principle and application of DSP is 51, including theory classes of 34 hours and practice classes of 17 hours. The practice part accounts for one third of the total class hours. This provides students with adequate opportunities to train and strengthen their operational abilities.

Teaching Means. The multimedia teaching is the mainstream of teaching means reform. Multimedia tools should be properly used to implement the optimal teaching effect, so as to seek innovation points and breakthrough for the teaching reform. Our research group has designed and is about to finish multimedia teaching courseware and website design. Furthermore, the teaching method combining classroom blackboard-writing, multi-media teaching and network teaching should be carried out.

Teaching Methods. In teaching Principle and Application of DSP, the heuristic method, the question headline and discussion-based teaching method are adopted. Research background of relevant technologies is always introduced to guide students to explore and think, and practical engineering projects are imported in due time to broaden students' thinking. On the basis of the teaching content, problems are well prepared to inspire students to think and arouse their learning desire, from passive learning to active learning.

Reform of teaching methods and teaching means is significant to enrich classroom atmosphere, activate students' thinking and stimulate students' learning interest.

\section{Reform of Practical Teaching}

The practical teaching is the indispensable link in the theoretical teaching. In order to improve students' ability of applying knowledge and their engineering quality, we absorb advanced experimental teaching ideas and thoughts, combine theoretical teaching with experimental teaching organically, reform experimental teaching gradually, and write the book TMS320C5402DSP Reference Book for Experimental Teaching. According to characteristics of the DSP technology, the practical teaching is divided into the basic experimental teaching and the curriculum design.

4.1 Success or failure of the experiment teaching reform in the basic practical teaching depends largely on the reform of the experimental teaching content. The original experiment teaching content is the verification experiments. Verification experiments are designed to enable students to master the digital signal processing algorithms. In verification experiments, students follow the steps in the lab lecture notes, and in the experiment process they mainly operate rather than think; in some experiments, even though they don't understand related experimental principles, they can complete the experiments and test reports. This makes verification experiments less attractive to students and causes students not enthusiastic to laboratory courses. Therefore, it is necessary to reform experiment teaching contents 
and methods.

Experiment content is modified from the simple verification experiment to several experiments, namely the verification experiment, the design experiment and the comprehensive experiment. The verification experiment is timely performed after the corresponding theoretical knowledge is taught, so that practice can be combined with theoretical knowledge. They can promote each other and enable students to consolidate and improve their mastery degree of theoretical knowledge. In the design experiment, the DSP experiment box is used. At present, the experiment has penetrated into classroom teaching, and the intelligent instrument laboratory is fully opened for students; it is convenient for students to learn and design DSP, meanwhile, reference programs of basic modules are also provided for them. In addition to compulsory verification and design experiments, alternative comprehensive experiments are also provided for fast-learned students. Comprehensive experiments are assigned by experimental teachers in the form of homework, and students are required to use the existing instruments, equipment and materials in the laboratory, design experimental schemes and finish experiment tasks by themselves.

4.2 Curriculum design is designed to enable students to use DSP chips skillfully, and to cultivate and train students' innovative thinking and abilities; thus 36 students are divided into 12 groups and 12 different design subjects are assigned to be completed in their spare time.

In the comprehensive curriculum design, students search information and lay down design schemes under teachers' guidance until they complete the design task. Through the comprehensive curriculum design, students are trained to use comprehensively theoretical knowledge to analyze and solve problems and to strengthen their practical hands-on abilities and the teamwork spirit, so as to make them grasp the method for subject study and lay a good foundation for graduation design and future work.

\section{Reform of Assessment Method}

Theoretical examination is weakened, while practical ability assessment is strengthened as well as process assessment.

The end-of-term scoring formula is: the total score $=$ end-of-term theoretical examination score $\times 40 \%+$ practical assessment score $\times 40 \%+$ daily performance score $\times 20 \%$

\section{References}

[1] Simom Haykin, and Barry Van Veen, Signals and Systems, 2nd ed, Beijing: Electronics Industry Press, 2003.

[2] Alan V. Oppenhein, Alan S. Will sky, and S. Hamid Nawab, Signalsand Systems, 2nd ed., Beijing: Electronics Industry Press, 2009.

[3] Charles L. Phillips, John M. Parr, and Eve A. Riskin, Signals, Systems, and Transforms, 3rd ed., Beijing: Machinery Industry Press, 2004.

[4] Zheng Nanling, and Chen Hong, Diginal Signal Processing, Beijing: Qinghua university Press, 2007.

[5] Chen Peiqing, Diginal Signal Processing, 3th ed., Beijing: Qinghua university Press, 2007.

[6] Yin Weimin, Ouyang Hua, and Qian Mei, Diginal Signal Processing, Beijing: Machinery Industry Press, 2011.

[7] Yao Tianren, and Jiang Taihui, Diginal Signal Processing, 2nd ed.Wuhan: Huazhong university of science and technology Press, 2000.

[8] Alan V. Oppenheim, Discrete-Time Signal Processing, 2nd ed, Prentice Hall, 1999. 
[9] Liu Hong-sheng, Zhu Xue-yong, and Peng Qi-cong, "Discussion of Different Teaching Methods of Overlap Content in 'Signal and System' and 'Digital Signal Processing'," Journal of Electrical \& Electronic Education, vol. 26, Jun. 2004, PP. 40-42.

[10] Luo Yi, "Research and Practice of Integration of Two Courses 'Signals and Systems' and 'Digital Signal Processig,,' Journal of Jishou University, vol. 32, Jan 2011, PP. 117-119.

[11]Zhang Yongrui, and Zhang Ni, "A Conformity Scheme for the Teaching Content of the two Courses 'Signal and system' \& 'Digital Signal Processing,,' Journal of Electrical \& Electronic Education, vol. 23, Feb. 2001, PP. 10-12.

[12] Li Jun sheng, Zhang Lichen, and Jiang Xiaoyan, "Reorganization and Optimization of Circuit Analysis and Signals and Systems and Digital Signal Processing," Journal of Changzhou Institute of Technology, vol. 22, Jun. 2009, PP. 89-92.

[13]Zhang Ai-hua, Dong Xiu-jie, and Gao Hui, "Reform and Practice on Curriculum Group of Signal Processing”, Journal of Electrical \& Electronic Education, vol. 32, Aug. 2010, PP. 36-38.

[14] Li Jie, Cao Xinyan, and Zhang Meng, "Search on the Teaching Reform of Signals and Systems Processing," Jounal of Changchun University, vol. 15, May. 2007, PP. 35-37

[15] Ma Sai, Li Fangneng, and Wu Zhengguo, "Exploration of the teaching reform and the establishment of the curriculum group of signal and system," Journal of higher education research, vol. 33, Jan. 2010, PP. 102-104.

[16]Huang Xiangsheng, "The Discussion on Several Problems about the Key Construction Curriculum Group of 'Signal and System'," Journal of East China Instituti Technology (Social Science), vol. 26, Apr.2007, PP. 418-421.

[17]Han Ping, Ni Yude, and Su Zhigang, "Construction and Practice of Signal Curriculum Group," Journal of Electrical \& Electronic Education, vol. 31, Jan. 2009, PP. 10-11.

[18] Li Min, and Chen Xinwen, "Exploration of Practical Teaching Reform on Curriculum Group of Signal Processing,” Journal of Dalian Nationalities University, vol. 10, Jan. 2008, PP. 91-93. 